\title{
Informing the population in case of extraordinary events by means of digital video broadcasting - terrestrial
}

\author{
P. Senovsky \& D. Rehak \\ Department of Civil Protection, Faculty of Safety Engineering, \\ VSB - Technical University of Ostrava, Czech Republic
}

\begin{abstract}
Timely and clearly transmitted information about the nature of threats is a basic tool to assist the minimization of consequences of extraordinary events from the point of view of both prevention of loss of life (e.g. in a form of evacuation) and minimization of damage to property (i.e. by implementing protective measures in the threatened area). Informing the population is realized in many available ways and by many available means, e.g. by nationwide networks of television and radio stations, by public address systems in towns, municipalities and facilities or by portable public address devices. However, a significant problem emerges in the course of evaluation of efficiency of these means especially in the area of audibility and intelligibility.

The aim of the article is the presentation of a new way of informing the public in the course of extraordinary events using the existing DVB-T infrastructure. For this way of informing, an appropriately equipped broadcasting station and installation of an encoder between the broadcasting station and a multiplexer are necessary. The stated solution thus will make it possible to add information in voice to TV or radio broadcasting. This information then can be received by television (after adding an additional decoder) and radio receivers, which provides the high intelligibility of transmitted information.

Keywords: population protection, informing, DVB-T, evacuation.
\end{abstract}

\section{Introduction}

The problems of effective informing the population about impending dangers have already occupied the minds of rescuers for several decades. In the course of 
development, a unified warning and notification system covering more than 90 per cent of the Czech Republic's area was introduced. Catastrophic floods that occurred in the Czech Republic in the years 1997 and 2002 have proved clearly the capabilities but also the limits of the existing solution - it is able to warn effectively and thus to minimize loss of life, but it does not furnish information that has such quality that can contribute to the minimization of other damage in proper time.

For this reason, alternative ways to inform the population are being searched. This article focuses just on one of these alternative ways, namely the use of digital video broadcasting - terrestrial (henceforth referred to as DVB-T) in the transmission of security-oriented information to households.

\section{Influence of warning on flood damage}

In the year 2004, DEFRA published an extensive study [1] on immeasurable impacts of floods on populations. Altogether three questionnaire surveys (two pilot studies and the main study) focused on flood-affected and flood-threatened populations were carried out. The study was performed in areas of Great Britain affected by floods in the period from 1999 to 2001. On the whole, about 1500 respondents were approached and the questionnaire was returned by 75 per cent of them.

The study of DEFRA has proved that floods affect human health; nevertheless, these impacts are usually neither too serious nor long-term - the majority of the impacts disappear in six months. What is interesting is also the survey concerning defence measures adopted by respondents (see Table 1).

Table 1: Flooding vs. threatening - implementation of defence measures (DEFRA [1]).

\begin{tabular}{|l|c|c|}
\hline Measure & Flooding & Threat \\
\hline Flood insurance & $60 \%$ & $44 \%$ \\
\hline Flood warning monitoring & $51 \%$ & $48 \%$ \\
\hline Moving valuable items upstairs & $36 \%$ & $18 \%$ \\
\hline Sandbags on property & $25 \%$ & $15 \%$ \\
\hline Sewerage maintenance & $22 \%$ & $21 \%$ \\
\hline
\end{tabular}

It shows that people having flood practical experience are more willing to invest in protective measures than those who live in flood-threatened areas but who have not been affected by floods yet.

Similar conclusions are drawn in a study [2] within the MICRODIS project, mapping the consequences of floods on population health in Germany, France and Italy.

The examination of damage that can be prevented by the implementation of active measures to minimize damage after warning of an impending danger is interesting as well. Penning-Rowsell and Green [3] published a formula for the calculation of estimated flood damage avoided (FDA) as a consequence of 
warning and that formula was gradually modified to the form of eq. (1) enforced for the evaluation of avoidable damage. A model described by eq. (1) is promoted by the UK Environment Agency as re-calibrated FHRC model [4].

$$
F D A=(T P D \cdot P I D \cdot M I D) \cdot R A S \cdot P H E
$$

where $F D A=$ estimated flood damage avoided as a result of the warning [£]; $T P D=$ total potential damage (e.g. total potential monetary value of damage to buildings and contents inventory) $[£] ; P I D=$ potential inventory damage (potential monetary value of damage to contents inventory items) $[£] ; M I D=$ movable inventory damage (potential monetary value of damage to moveable contents inventory items); $R A S=$ reliability of the flood warning process (e.g. the proportion of households in the area that have been warned with sufficient lead time to take action) and $P H E=$ the proportion of households that are able to respond effectively.

For the Czech Republic (henceforth referred to as $\mathrm{CR}$ ), the values of individual parameters will be different. However, we can make per cent estimates of RAS and PHE parameters, and based on them we can estimate the percentage of damage that we are able to avoid.

To estimate the reliability of warning, the quality of information transmitted to the threatened population will be determinant. The essential tool that is used for this purpose is a unified warning and notification system. This consists of both rotational sirens and so-called electronic sirens. The difference between them consists just in the "quality" of transmitted information.

Modern systems are, with regard to the financial demands of implementation, primarily installed in town centres - as places with the highest density of population.

The determination of the PHE parameter is problematic, because the ability of the population to respond effectively is limited, to a certain extent, by quite a number of factors:

- warning timeliness - it has to be time to implement protective measures,

- knowledge and material means - the warned has to know which of measures are effective to implement and has to have means (e.g. sandbags) to implement them,

- willingness to implement the measures.

As indicated in Table 1, the willingness to implement measures depends on experience of floods. With a slight exaggeration it can be said that protective measures are implemented by all who have already been flooded and by none of those who have not been flooded.

It will not be easy to determine the exact value of the parameter for the CR; however it can be expected that it will be rather smaller than larger. We can consider realistically a value ranging from 0.2 to 0.35 , i.e. the number that is in relation to the original estimates of PHE in Great Britain. The setting of values of RAS $=0.9$ and $\mathrm{PHE}=0.2$ will mean that we shall be able to prevent, by means of estimation, roughly about 18 per cent of avoidable damage.

Nevertheless, the above-mentioned facts do not provide any solution for improving the situation. If the population is prepared to prevent merely 18 per 
cent of damage, which may be technically prevented, then it is, on the one hand, bad news, because it indicates low effectiveness, but on the other hand, this piece of data can be taken also positively because there is much room for improvement here.

\section{Current system of warning and informing the citizens of the Czech Republic}

The warning of the CR's population is carried out by means of a unified warning and notification system, for which the Fire and Rescue Service of the Czech Republic is technically, operationally and organizationally responsible. The subsequent informing is done not only through this system, but also by means of the mass media (television and radio), the operators of which are obliged to broadcast emergency information. However, the citizens of the Czech Republic have to be warned and informed about impending dangers both in the territory of the CR and abroad during their stays there. For this purpose, the Ministry of Foreign Affairs of the CR created a special registration system DROZD (Voluntary registration of citizens travelling abroad), which, in case of serious danger, makes it possible to send mass warning messages to citizens abroad. The system of warning and informing of citizens of the CR can be seen in Figure 1.

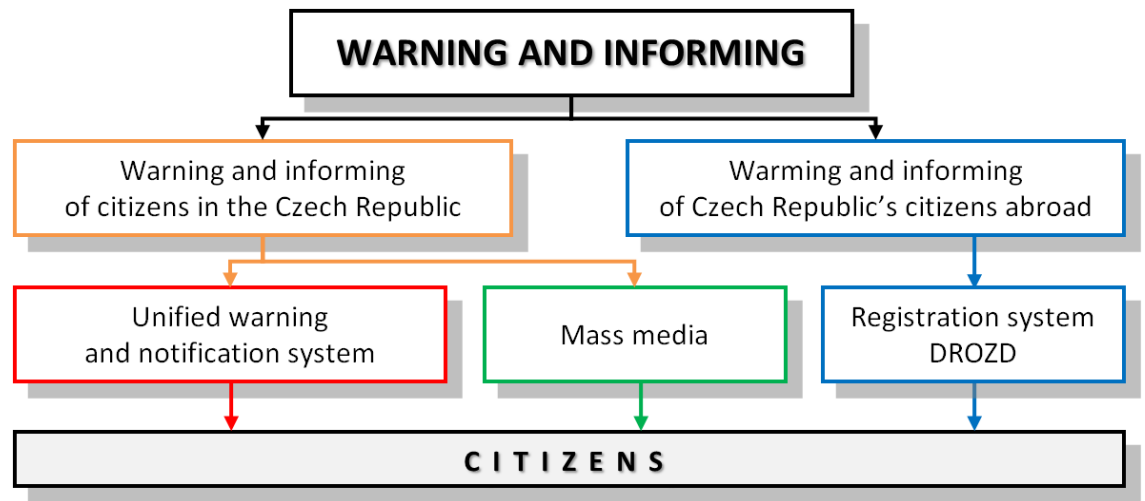

Figure 1: System of warning and informing the citizens of the Czech Republic [5].

According to Evaluation of the Conception of Protection of the Population until 2013 with an Outlook to 2020 [6], 90 per cent of the Czech Republic's area is covered by the unified warning system. A large part of it consists of electrical rotational sirens (about 84.7\%), which are not however able to transmit comprehensive information - merely a warning signal. In recent years, these systems have been gradually replaced by more modern electronic sirens. With regard to financial demands, this transition is however very slow, and thus also in the near future, signals of electrical rotational sirens will be the predominant form of warning. 
The quality of information furnished to threatened citizens will thus have a decisive influence on their ability to evaluate the real level of the threat and to decide thus the optimal way of protection of life, health and property.

The 2008/2009 economic crisis as well as the current situation that seems to be the beginning of a long-term eurozone monetary crisis has affected negatively public budgets; therefore, any too rapid replacement of sirens by more modern types cannot be expected in the future. For this reason, any rapid increase in the quality of information transmitted by the unified warning and notification system as a tool applicable to damage minimization (FDA) cannot be assumed. Then it is necessary to look for and to implement alternative solutions that are able to deliver good-quality information to threatened places in proper time and at lower costs.

To propose an effective measure, it is necessary to consider the fact that an extraordinary event is located firmly in time and space. The space is covered, to a certain extent, by electronic sirens that are able to transmit good-quality information; the number of them is however relatively small and does not grow too much. Although the emergency services of the Integrated Rescue System are equipped with mobile means for warning, the transmission of information represents the necessity of physical presence of a vehicle which making the rounds in delimited areas and transmitting necessary information. Negative aspects are attendance - time delay and limited number of vehicles.

Although information transmitted like that can be of relatively good quality, the information is not transmitted when the user of the information really needs it or wants to have it, but it is transmitted when physically possible.

In the CR, many experiments with technologies focused on removing or at least minimizing these disadvantages have been conducted. With reference to the wide use of mobiles, first of all, there is a possibility of using SMS messages that will be sent to the threatened area.

The first projects transmitted information using SMS to those people who had registered as volunteers to receive such information. As an example, the system DROZD operated by the Ministry of Foreign Affairs [7] can be given. In this case, information is transmitted according to the destination countries of travellers.

Information is transmitted by SMS automatically also by some rather small insurance companies. As an example the service MeteoUNIQUA [8] of the insurance company UNIQUA can be presented. The assignment to the place of interest is performed by means of a zip code (ZC), which is registered in an insurance agreement. However, in this case the insurance company is a mere information intermediary. The insurance company draws the information from other sources, and thus a delay is created, which may in case of extraordinary events of the type of flash flood cause that the transmitted information will be hopelessly out of date at the moment of transmission. The second problem is that the registered $\mathrm{ZC}$ need not correspond to the area in which the given person lives or is at the given moment, or does not cover the whole property that is threatened (e.g. chalet). For this reason, large insurance companies do not provide such services yet. 
By means of SMS, some towns provide information as well. The town of Chrudim with its application InfoKanál is a good example. In this case, inhabitants register as volunteers to receive information through SMS. The town is the primary source of information for the inhabitants. Thus if the town is able to deliver information to its inhabitants - then the information will be of best possible quality.

The problem is however just this voluntariness to receive information. If the information is to be available really anywhere, then SMS messages have to be delivered to all mobile devices occurring in the threatened area or having a legitimate interest in the threatened area.

The other part of the requirement cannot be fulfilled without co-operation on the part of a potential user of information; nevertheless, information distribution to the devices in a certain area can be technically ensured relatively simply. For operation in operators' networks, mobile devices have to be connected to base transceiver stations (henceforth referred to as BTS), which are installed throughout the country. It is stated that the range of BTSs is from 27 (microcell) to $35 \mathrm{~km}$ (macrocell, umbrella cell). The transmission of information by SMS would have to be done on the part of the operator. Information thus will be certainly delivered to the area of interest, but it should be noted that the operator is a mere information intermediary. Thus, in this case the problem is the transmission of information from the source of the information to the operator.

Municipalities themselves can, in compliance with valid legislation, establish and operate wireless local information systems (henceforth referred to as WLIS) that, according to the General Authorisation VO-R/2/01.2010-1 [9], operate on a frequency of $70 \mathrm{MHz}$ within a distance of $15 \mathrm{~km}$ and are designed for warning physical and legal entities in the covered area. The number of WLISs registered in the Czech Republic is 2122 (as of 8 December 2011).

BMISs thus replace the older networks of local wire broadcasting. The signal travels wirelessly in an analogue form and is received by individual BMIS terminal points that work further with it, usually in a form of signal sound reproduction. If we omit some possible security problems (zero safeguarding) and possibilities of interference among individual BMIS networks, we can say that it is a case of modern systems that can be used for warning and notification, the reliability of which is however considerably limited and the correct functionality of which when really needed cannot be guaranteed.

\section{Connection of BMIS and use of digital video broadcasting - terrestrial}

The above-mentioned disadvantages are, to a considerable extent, removed by connection of the wireless local information system by means of digital video broadcasting- terrestrial. The key advantage is above all a relatively easy and thus also cheap configuration of connection of local information systems, including the interconnection with the system of unified notification and warning of citizens. 
From the technical point of view, the interconnection can be implemented as follows: in the point of compression infrastructure of the DVB-T multiplexer operator, before the multiplexer an encoder is inserted; one input of it is connected to the group coder, the other input of the encoder is connected to the personal computer, which is connected to the Internet. On the part of percipients, a DVB-T receiver is there, the first low-frequency output of which is connected to the decoder and the other low-frequency output is connected to the input of a high power amplifier, the output of which is connected to one or more loudspeakers.

The advantages of connection according to the engineering solution consist in the fact that the multiplexer of DVB-T is able to provide the good-quality signal to more localities. Although the DVB-T transmitter range depends directly on the terrain, we can generally assume the real range of the transmitter in the order of several ten kilometres. In comparison with the BMIS, a terminal device is a television directly in the dwelling. From the point of view of sound quality, the transmitted information thus will be of incomparably higher quality than in the case of use of common terminal points of warning and notification systems.

In comparison with the BMIS, the proposed engineering solution is suitable especially for covering rather large towns, where implementation is, with regard to the low allowed output of BMIS, usually problematic (see Figure 2).

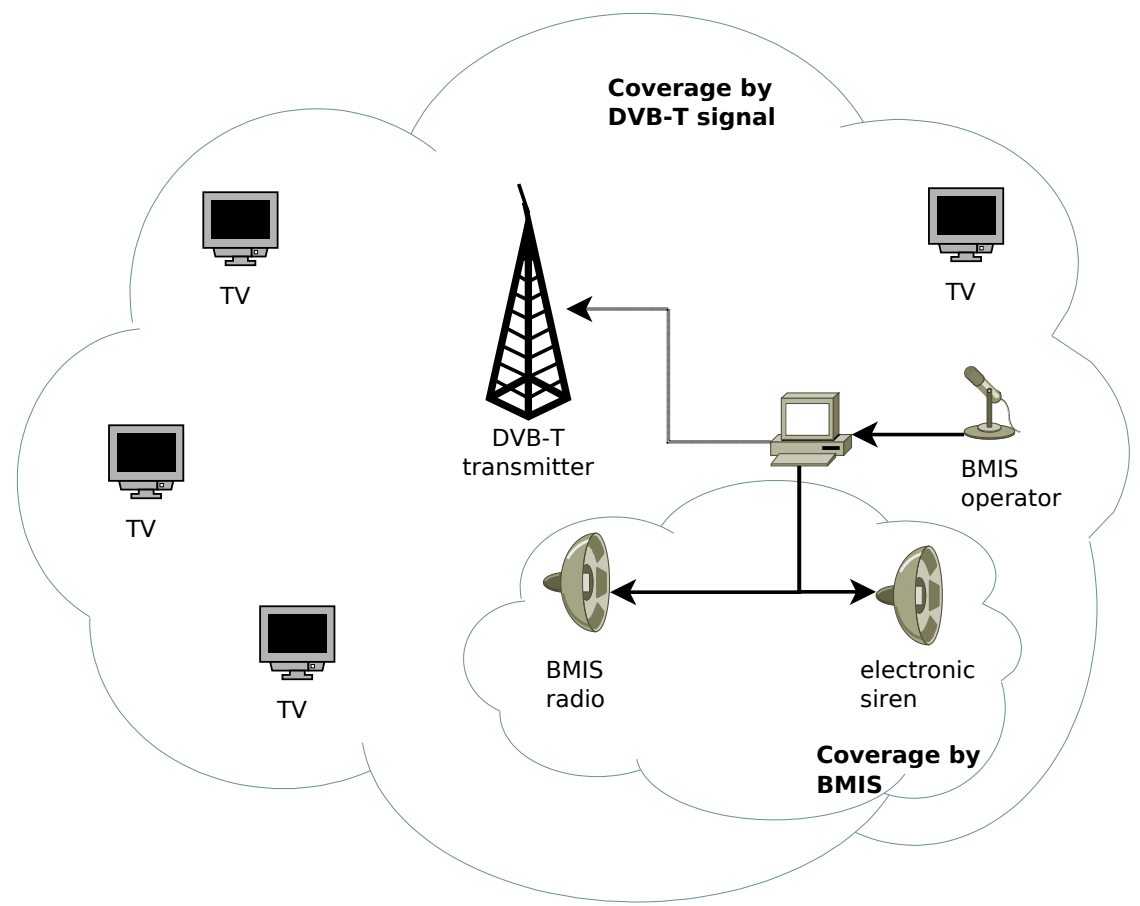

Figure 2: Diagram of integration of the BMIS with the notification system using DVB-T. 
Modification in DVB-T on the part of a "modifier" is thus technically easy. However, an agreement with the operator of digital terrestrial broadcasting is required; in this context, the legislation does not impose any obligation on the operator of DVB-T. Moreover, signal integration does not interfere the broadcasting of common television and radio stations; modification in the broadcasting of some of the stations is not acceptable from the point of view of Act on electronic communications [10]. For broadcasting, the operator of the given station is responsible, and in this case as a result of integration with the BMIS the operator would lose full control over broadcasting because other entities could enter into it.

Although the Act on radio and television broadcasting [11] in Section 32 specifies the possibility of use of television broadcasting by state authorities and local self-government authorities in public interest in urgent cases for transmitting important and urgent announcements in connection with the promulgation of state of emergency, state of threat to the State, state of war, and announcement of measures to protect public health, the operator of the station has, even in such cases, the full control over broadcasting with the exception of the content of such announcements.

In existing prototypes that were designed and manufactured by the joint-stock company B PLUS TV, the integration functions as follows: the existing broadcasting is merely a carrier of additional (voice) information. This however means that the majority of television receivers and set-top boxes are not able to interpret the signal propagated like that in full. The main broadcasting of classical television and radio stations is interpreted correctly, but additional information in the signal is ignored. For interpretation, an additional decoder interpreting the DVB-T signal travelling to the terminal device has to be used at present.

Such a decoder would have to be assigned to each terminal device, which is quite a large disadvantage of this otherwise interesting device. Although decoders are not expensive, B PLUS TV states that the price is of the order of several hundred crowns; nevertheless, we can hardly force end users into such investment. Alternatively, devices can be provided e.g. by municipal and regional authorities to improve the informedness of populations in emergency situations. The installation and the use of the devices will be again upon end users. Diagrammatic representation of the new solution is given in Figure 1.

An alternative source of information is classical television broadcasting as well. However, in terms of informedness of the population concerning extraordinary events, the problem is a too large area to which information is broadcast. From the point of view of television broadcasting, the smallest territorial unit is a region.

\section{Conclusion}

The existing notification and warning system covers more than 90 per cent of the Czech Republic's area. In the previous years when coping with extraordinary events of large extent, such as floods, it has been proved that this system is very 
effective in preventing the loss of life. Although the life is the most precious thing we have, this is merely a part of damage brought by the events of large extent.

What is also decisive of the speed and effectiveness of restoration is the way in which threatened people themselves face up danger from the point of view of implementation of possible protective measures. For these activities, the transmission of comprehensive, high-quality information on the nature of an impending danger and the way of protection against it in sufficient advance are however required.

In addition to the use of standard terminal points of the warning and local public address systems, the digitalization of television broadcasting has brought a new possibility, namely the adding of information in a voice form to the data stream of common DVB-T. The engineering solution is not in any way difficult (and expensive) and can be integrated with the existing BMIS. However, in contrast to the BMIS, the area covered by this broadcasting expands and the number of terminal points increases, because television receivers and set-top boxes are used as terminal points. Besides equipment for common receiving DVB-T, a decoder that will be able to process the additional information is necessary.

The requirement for the installation of another device for work with the digital television signal is simultaneously the greatest weakness of the proposed solution, because it assumes an investment (although low) on the part of the end user, and subsequently the correct installation of the device, which may be a problem for less technically proficient people.

Nevertheless, this possibility is very interesting because by means of this new technology, in case of need, information can be transmitted directly to individual households in high quality, not distorted by noise from the external world.

\section{Acknowledgement}

This contribution was prepared as part of the grant project of the Ministry of the Interior of the Czech Republic under number VF20112015018, titled "Security of population - crisis management".

\section{References}

[1] DEFRA. The Appraisal of Human related Intangible Impacts of Flooding $R \& D$ Technical Report FD2005/TR. London, Great Britain, 352 p., 2004.

[2] Jakubicka, T. et al. Health impacts of floods in Europe - Data gaps and information needs from a spatial perspective. Universitätsklinikum Heidelberg: Heidelberg, 43 p., 2011.

[3] Penning-Rowsell, E. C., Green, C. New Insights into the Appraisal of Flood - Alleviation Benefits: (1) Flood Damage and Flood Loss Information. Water and Environment Journal. 14(5), pp. 347-353, 2000. DOI: 10.1111/j.1747-6593.2000.tb00272.x. 
[4] Lany, P. et al. Reliability in Flood Incident Management Planning Final Report-Part A: Guidance. Environment Agency: Bristol, 65 p., 2009.

[5] Adamec, V., Řehák, D., Černá, L. Základy organizace a ř́zení bezpečnosti $v$ České republice (Fundamentals of Organization and Management of Security in the Czech Republic). Sdružení požárního a bezpečnostního inženýrství: Ostrava, 140 p., 2012 (in Czech).

[6] General Directorate of Fire and Rescue Service of the Czech Republic. Evaluation of the Conception of Protection of the Population until 2013 with an Outlook to 2020 (in Czech). Prague, 51 p., 2008.

[7] Ministry of Foreign Affairs. DROZD web page, Prague, drozd.mzv.cz

[8] UNIQUA. MeteoUNIQUA, Prague, sec.uniqa.cz/meteo

[9] ČTÚ. General Authorisation No. VO-R/2/01.2010-1 for the use of radio frequencies and for the operation of the stations of wireless local information systems (BMIS) in the $70 \mathrm{MHz}$ frequency band (in Czech). Prague 2010, www.ctu.cz/cs/download/oop/rok_2010/vo-r_02-01_201001.pdf

[10] Czech Republic. Act 127 of 22 February 2005 on electronic communications (in Czech). Sbírka zákonů ČR, 2005(43).

[11] Czech Republic. Act 231 of 17 May 2001 on radio and television broadcasting. Sbirka zákonů $\check{C} R, 2001(87)$. 